\title{
Therapeutic efficacy of a novel humanized antibody-drug conjugate recognizing plexin-semaphorin-integrin domain in the RON receptor for targeted cancer therapy
}

Xiang-Min Tong ${ }^{1 \dagger}$, Liang Feng ${ }^{2 \dagger}$, Sreedhar Reddy Suthe ${ }^{3}$, Tian-Hao Weng ${ }^{4,5}$, Chen-Yu Hu ${ }^{4,5}$, Yi-Zhi Liu ${ }^{4,5}$, Zhi-Gang Wu ${ }^{4,5}$, Ming-Hai Wang ${ }^{1,2,3,4^{*}}$ (D) and Hang-Ping Yao ${ }^{4,5^{*}}$

\begin{abstract}
Background: Antibody-drug conjugates (ADCs) targeting the RON receptor, a tumorigenic factor contributing to cancer malignancy, has been considered as a novel strategy for cancer therapy. Here we describe a humanized antibody recognizing the RON plexin-semaphorin-integrin (PSI) domain with increased drug delivery capability for potential clinical application.

Method: Monoclonal antibody PCM5B14 specific to the human and monkey RON PSI domain was generated and characterized by various immunological methods. Humanized antibody H5B14 was created by grafting PCM5B14 complementarity-determining regions into human $\mathrm{lgG} 1 / \mathrm{K}$ acceptor frameworks and conjugated with monomethyl auristatin E and duocarmycin to form two H5B14-based ADCs. Stability of H5B14-based ADCs in human plasma was measured using hydrophobic interaction chromatography. Various biochemical and biological assays were used to determine ADC- regulated RON internalization, cell viability, spheroid formation, and death of cancer stem-like cells. Efficacies of H5B14-based ADCs in vivo were validated using tumor xenograft models. Maximal tolerated doses of H5B14-based ADCs were established in mice.

Results: H5B14 was highly specific to the human RON PSI domain and superior over other anti-RON ADCs in induction of RON internalization in various cancer cell lines tested. H5B14-based ADCS had a drug to antibody ratio of $\sim 3.70: 1$ and were stable in human plasma with a minimal dissociation within a 10-day period. Functionally, H5B14-mediated drug delivery decreased cell viability at early stages with an average $\mathrm{IC}_{50}$ at $\sim 20 \mathrm{nM}$ in multiple cancer cell lines examined. H5B14-based ADCs also inhibited spheroid formation and caused death of cancer stemlike cells with $\mathrm{RON}^{+} / \mathrm{CD}_{4} 4^{+} / \mathrm{ESA}^{+}$phenotypes. In vivo, H5B14-based ADCs in a single injection inhibited tumor xenograft growth mediated by multiple cancer cell lines. Tumoristatic concentrations calculated from xenograft tumor models were in the range of 0.63 to $2.0 \mathrm{mg} / \mathrm{kg}$ bodyweight. Significantly, H5B14-based ADCs were capable of eradicating tumors at variable levels across multiple xenograft models regardless their malignant statuses. Toxicologically, H5B14-based ADCs were well tolerated in mice up to $60 \mathrm{mg} / \mathrm{kg}$.

(Continued on next page)
\end{abstract}

\footnotetext{
*Correspondence: minghai.wang@ttuhsc.edu; yaohangping@zju.edu.cn

${ }^{+}$Xiang-Min Tong and Liang Feng contributed equally to this work.

'Department of Hematology, Zhejiang Provincial People's Hospital,

Hangzhou Medical College, Hangzhou, China

${ }^{4}$ State Key Laboratory for Diagnosis \& Treatment of Infectious Diseases, First

Affiliated Hospital, Zhejiang University School of Medicine, Hangzhou, China

Full list of author information is available at the end of the article
}

(c) The Author(s). 2019 Open Access This article is distributed under the terms of the Creative Commons Attribution 4.0 International License (http://creativecommons.org/licenses/by/4.0/), which permits unrestricted use, distribution, and

reproduction in any medium, provided you give appropriate credit to the original author(s) and the source, provide a link to the Creative Commons license, and indicate if changes were made. The Creative Commons Public Domain Dedication waiver (http://creativecommons.org/publicdomain/zero/1.0/) applies to the data made available in this article, unless otherwise stated. 
(Continued from previous page)

Conclusion: H5B14-based ADCs targeting the RON PSI domain are superior in inducing RON internalization, leading to robust drug delivery and overall inhibition and eradication of tumors in multiple xenograft models. These findings warrant H5B14-based ADCs for clinical trials in the future.

Keywords: RON receptor tyrosine kinase, PSI domain, Monoclonal antibody, Humanization, Antibody-drug conjugates, Receptor internalization, Epithelial cancer, cancer stem cells, Tumor xenograft model, Therapeutic efficacy

\section{Introduction}

Antibody-drug conjugate (ADC) targeting the RON receptor tyrosine kinase is a promising strategy for cancer therapy and currently is under intensive evaluation for potential clinical trials [1-6]. RON belongs to the MET proto-oncogene family, which contributes to cancer tumorigenesis, malignancy, and chemoresistance [7, 8]. Pathologically, RON is overexpressed in various types of cancers including colon, lung, breast, and pancreatic tumors [9-12]. Increased RON expression also is an indicator for the shortened survival of certain types of cancer patients [13]. At the cellular level, constitutive RON activation transduces signaling that promotes epithelial to mesenchymal transition leading to aggressive phenotypes [14-18]. Aberrant RON expression also is associated with production of truncated/splicing oncogenic variants [19-22], which facilitates cancer cell invasive growth and chemoresistance [19-22]. Clearly, the pathogenic features of RON provide the molecular basis for targeting RON for cancer therapy.

For the last decade, we have focused on development of RON-specific ADCs for cancer therapy [1-6]. By characterizing monoclonal antibodies (mAbs) specific to RON [23-25], we have selected lead candidates based on their antigen specificity, binding sensitivity, and suitability as biotherapeutics for ADC development [1-6]. Structurally, ADCs are composed of an antigen-specific antibody conjugated with a highly potent cytotoxin such as maytansinoid derivative 1 (DM1), monomethyl auristatin E (MMAE), and duocarmycin (DCM) through a chemical and/or protease cleavable linker [26, 27]. Various factors, including antigen expression, antibody-binding affinity, antibody-induced target internalization, cytotoxic compound selection, chemical linker property, all influence ADC pharmacokinetics and therapeutic efficacy $[26,27]$. Thus, biochemical and pharmaceutical optimization of ADCs is essential for successful development of lead candidates for clinical trials and patient application.

Ligand-dependent activation causes RON endocytosis into cytoplasmic compartment [23, 24]. This effect also is observed upon antibody binding to the RON extracellular domains $[1-6,28,29]$, which is the first step required for delivery of cytotoxic drugs for cancer cell killing. In this sense, selection of mAbs that are capable of inducting robust RON internalization for drug delivery is the key step for the validation of RON-targeted ADCs. The extracellular sequences in the RON $\beta$-chain contain a semaphorin (SEMA) domain followed by a plexin-semaphorin-integrin (PSI) domain and three immunoglobulin-like plexin and transcription (IPT) motifs $[7,8,30]$. The SEMA domain harbors a high-affinity ligand-binding pocket, which, upon ligand interaction, is capable of dimerizing $\mathrm{RON}$ for signaling transduction $[31,32]$. The PSI domain serves as a wedge between the SEMA domain and IPT motifs and facilitates the formation of a RON homodimer with interface formed by the SEMA domain [31, 32]. In this sense, the PSI domain is responsible for the correct positioning of the ligandbinding site of RON. Studies also observe that mAbs binding to the PSI domain cause a rapid MET internalization by cancer cells [33]. This suggests that the use of mAbs to target the PSI domain to induce receptor internalization could be a critical pharmaceutical approach for drug delivery.

The study presented here is about humanized $\mathrm{mAb}$ H5B14 specific to the PSI domain in induction of RON internalization and to validate the efficacy of H5B14based ADCs in inhibition and/or eradication of tumor xenografts in mouse models. We have previously shown that mAbs such as $\mathrm{Zt} / \mathrm{g} 4$ specific to the SEMA domain is capable of induction of RON internalization [1-6]. Consistent with these observations, Zt/g4-based ADCs are effective in inhibition and eradication of xenograft tumors derived from colon, breast, lung, and pancreatic cancer cell lines [1-6]. Currently, the role of the PSI domain in regulating RON internalization is unknown. Availability of our mAbs specific to the RON PSI domain such as H5B14 provides an opportunity to test whether this $\mathrm{mAb}$ is suitable candidate for development of RON-targeted ADCs for clinical application.

\section{Materials and methods}

\section{Cell lines, reagents, and animals}

Pancreatic adenocarcinoma (PAC) ASPC-1, Panc-1, BxPC-3, colorectal cancer LoVo, HT-29, HCT116, SW620, breast cancer MCF-7, T-47D, MDA-MB-231, Du4475, and lung cancer H1993, H358, H2228 cell lines 
were from American Type Cell Culture (ATCC, Manassas, VA). Additional PAC cell lines FG and L3.6pl were provided by Drs. A.M. Lowy (University of California at San Diego, San Diego, CA) and G.E. Gallick (University of Texas M.D. Anderson Cancer Center, Houston, TX), respectively. All cell lines were authenticated in 2015 with cytogenesis analysis performed by ATCC. Stable NIH3T3 cells expressing human, monkey, or mouse RON were used as previously described $[6,19]$. Mouse anti-RON mAbs Zt/g4, Zt/c1, Zt/c11, Zt/f2, Zt/f12, and rabbit IgG antibody $\mathrm{R} \# 5029$ against the RON Cterminus were used as previously described $[19,23]$. Female athymic nude mice at 6 weeks of age were from Taconic Biosciences [Granbury, NJ]. The use of mice was approved by the Texas Tech University institutional animal care committee.

\section{Generation of mouse mAbs specific to the RON PSI domain}

Synthetic peptides containing 42 amino acids from Gly $^{526}$ to Pro ${ }^{568}$ corresponding to the RON PSI domain [7] was conjugated to keyhole limpet hemocyanin and used as immunogens for Balb/c mice. After immunization, mice also were injected with NIH3T3-RON cells to boost immune response. Culture supernatants from individual hybridoma cell lines were screened for anti-RON reactivity. IgG antibodies were purified using protein G Sepharose columns as previously described [23].

\section{Assays for detecting mAbs specific to the RON PSI domain}

Purified RON proteins and its various isoforms including short-form RON (sf-RON), RON $\Delta 160$, RON $\Delta 110$, and RON $\Delta 75$ were used as previous described [19]. Purified human MET proteins containing the entire extracellular sequences were from Sino Biologicals [www.sinobiologi cal.com]. A direct enzyme-linked immunosorbent assay (ELISA) was used first to select mAbs specific to the RON PSI domain. Briefly, proteins at $1.5 \mu \mathrm{g}$ per $\mathrm{ml}$ were coated in triplicate in a 96-well ELISA plate followed by addition of individual mAbs at $2 \mu \mathrm{g} / \mathrm{ml}$. Goat anti-mouse IgG antibody coupled with horseradish peroxidase (HRP) was used as the detecting antibody. The reaction was measured with an ELISA reader. The positivity of mouse mAbs such as PCM5B14 to the RON PSI domain was further evaluated by immunoprecipitation and immunofluorescence analysis.

\section{Humanization of mouse PCM5B14 and generation of antibody-drug conjugators}

Antibody humanization was performed by grafting sequences from complementarity-determining regions (CDRs) of the light and heavy chains of PCM5B14 into human $\operatorname{IgG} 1 / \mathrm{\kappa}$ acceptor frameworks to generate five light chains and five heavy chains, which results in 25 different pairings of humanized PCM5B14 molecules $[6,34]$. The subclone H2L4 (designated as H5B14) was selected as the lead candidate. MMAE and DCM linked to a synthetic dipeptide liker (MC-VC-PAB0 from Concortis [www.concortis.com] were used for conjugation with H5B14 according to the manufacturer's instruction. Conjugation resulted in two H5B14-based ADCs: H5B14MMAE and H5B14-DCM. H5B14 conjugated with DM1 (H5B14-DM1) and Zt/g4 conjugated with MMAE (Zt/g4MMAE) also were prepared [1-3]. Control mouse IgG conjugated with MMAE (CmIgG-MMAE) served as the control. All conjugates were verified by hydrophobic interaction chromatography (HIC) for the drug to antibody ratio (DAR). All ADCs were sterilized through a filter and stored at $4{ }^{\circ} \mathrm{C}$ for further analysis.

\section{Assays for RON expression, internalization, and cell viability}

Expression of RON by cancer cell lines was determined by flow cytometric analysis using anti-RON mAb Zt/f2 [1-3]. Induction of RON internalization by H5B14 and other anti-RON mAbs was determined by immunofluorescence analysis as previously described [1-3]. The internalization efficacy $\left(\mathrm{IE}_{50}\right)$, defined as the time required for a $50 \%$ reduction of cell surface RON, was calculated as previously described [1-3]. Cell viability after individual ADC treatment was determined by the 3-[4, 5- dimethylthiazolyl-2]-2, 5diphenyltetrazolium bromide (MTT) assay. Cell death was validated by the trypan blue exclusion assay.

\section{Analysis of H5B14-based ADC stability in buffer and in human plasma}

H5B14-based ADCs at $10 \mu \mathrm{g}$ per ml were incubated in phosphate-buffered saline (PBS) at room temperature for 28 days. Samples were collected at different time intervals and measured by HIC for changes in DARs. H5B14-based ADCs at $10 \mu \mathrm{g}$ per $\mathrm{ml}$ also were incubated in $1 \mathrm{ml}$ fresh human plasma at $37^{\circ} \mathrm{C}$ for 10 days and then collected at different time points. Free MMAE and DCM were measured by using a liquid chromatography with tandem mass spectrometry method (LC-MS/MS) [35] with slight modifications [6].

\section{Generation of spheroids, isolation of cancer stem-like cells, and quantitation of cells expressing stem cell marker}

The spheroid formation derived from ASPC1, BxPc-3, and L3.6pl cell lines with or without H5B14-based ADC treatment was performed as previously described [5, 29]. PAC stem-like cells with $\mathrm{RON}^{+} / \mathrm{CD}_{4} 4^{+} /$epithelial specific antigen $[\mathrm{ESA}]^{+}$phenotypes (designated as $\mathrm{PAC}^{\mathrm{SL}}$ cells) were isolated from ASPC1, BxPC-3, and L3.6pl cell 
lines as previously described [5, 29]. For cell death, $\mathrm{PAC}^{\mathrm{SL}}$ cells were treated with H5B14-based ADCs for $72 \mathrm{~h}$ followed by the trypan blue exclusion assay. Flow cytometric analysis of FG cells expressing stem cell marker aldehyde dehydrogenase (ALDH) after H5B14based ADC treatment was performed by using ALDEFLUOR $^{\text {tm }}$ Kit (Stemcell Technologies, Cambridge, MA).

\section{Tumor xenograft model and H5B14-based ADC treatment} LoVo, H358, HT-29, L3.6pl, and T-47D cell lines were used in tumor xenograft model. Female athymic nude mice (ten mice per group) were injected with $5 \times 10^{6}$ cells in $0.1 \mathrm{ml}$ PBS into the subcutaneous space of the right flank as previously described [1-3]. Xenograft tumors mediated by LoVo cells served as the negative control. Mice were randomized into control and ADCtreatment groups (five animals per group). Treatment began when tumors had a mean volume of $\sim 150 \mathrm{~mm}^{3}$. A single dose of H5B14-MMAE or H5B14-DCM at 20 $\mathrm{mg} / \mathrm{kg}$ was injected through tail vein in a volume of 0.1 $\mathrm{ml}$ PBS. Tumor volumes were measured every 4 days and monitored up to 36 days. All mice were sacrificed at the end of study. Tumors from individual mice were collected and weighed to reach an average value for each group. The percentage of inhibition was calculated as previously described [1-3].

\section{Maximal tolerated doses of H5B14-based ADCs in mice}

Female athymic nude mice (five mice per group) were administrated with H5B14-based ADCs at 40, 60, 80, and $100 \mathrm{mg} / \mathrm{kg}$ in a single dose through the tail vein. Animals were monitored daily for activity, responsiveness, food consumption, bodyweight, and others. Mice were sacrificed at the end of the study.

\section{Statistical analysis}

The GraphPad Prism 7 software was used for statistical analysis. Results are shown as mean \pm SD. The data between control and experimental groups were compared using Student $t$ test. Statistical differences at $p<0.05$ were considered significant.

\section{Results}

\section{Humanization and characterization of $\mathrm{H} 5 \mathrm{~B} 14$ specific to the RON PSI domain}

Procedures to produce mouse mAb PCM5B14 specific to the RON PSI domain is illustrated in Additional file 1: Figure S1. Using RON, various RON isoforms, and the MET extracellular protein (Fig. 1a) as antigens in the ELISA assay, we confirmed that PCM5B14 is specific to the RON PSI domain but not to MET (Fig. 1b). Composition of amino acids from individual CDRs of PCM5B14 were obtained by sequence analysis. Schematic structures of CDRs from PCM5B14 grafted into both light and heavy chains of human IgG1/k acceptor frameworks are shown in Fig. 1c. A total of 25 pairs of humanized IgG1/K molecules were obtained from five light chains in combination with five heavy chains. Immunofluorescence analyses of individual humanized antibodies binding to cell surface RON in HT-29 cells in comparison with mouse PCM5B14 are shown in Fig. 1d. Analysis of antibody-binding affinities by individual humanized antibodies is presented in Fig. 1e and $\mathrm{f} . \mathrm{H} 5 \mathrm{~B} 14$, the humanized IgG1/K subclone H2L4 with the binding affinity of $0.35 \mu \mathrm{g}$ per $\mathrm{ml}$, was selected for further study. Large scale production of H5B14 up to $150 \mathrm{mg}$ IgG protein was achieved using HEK293 expression system [1-3]. H5B14 also recognized cynomolgus monkey RON with a binding affinity of $0.41 \mu \mathrm{g} / \mathrm{ml}$ but not mouse RON (Additional file 2: Figure S2).

\section{Superiority of H5B14 in induction of RON internalization for drug delivery}

H358, HT-29, L3.6pl, and T-47D cell lines expressing variable levels of RON [1-6] were used to evaluate the effectiveness of H5B14 in induction of RON internalization (Fig. 2). The calculated $\mathrm{IE}_{50}$ values were $5.3 \mathrm{~h}$ for HT-29; $8.2 \mathrm{~h}$ for L3.6pl; $7.9 \mathrm{~h}$ for H358; and $8.6 \mathrm{~h}$ for T47D cells, respectively. Similar results were also observed when PCM5B14 was used (Fig. 2). These results suggest that $\mathrm{H} 5 \mathrm{~B} 14$ has the ability to cause a rapid RON internalization with more than $50 \%$ RON internalized within a $10 \mathrm{~h}$ period.

We then determined whether H5B14-induced RON internalization is superior over other anti-RON mAbs that recognize the SEMA domain or the IPT motifs. Results for such comparisons were shown in Additional file 6: Table S1. Among eight RON-expressing cell lines tested, average $\mathrm{IE}_{50}$ values were $8.66 \mathrm{~h} \pm 2.36$ for PCM5B14 and $8.77 \mathrm{~h} \pm 2.39$ for $\mathrm{H} 5 \mathrm{~B} 14$, respectively. In contrast, average $\mathrm{IE}_{50}$ values for $\mathrm{Zt} / \mathrm{g} 4$ and $\mathrm{Zt} / \mathrm{f1} 2$ that recognize the sema domain were $14.90 \mathrm{~h} \pm 6.23$ and $17.12 \mathrm{~h} \pm 3.62$, respectively. The effect of $\mathrm{Zt} / \mathrm{c} 1$, which recognizes the IPT motifs, appeared to be weak with an average $\mathrm{IE}_{50}$ value at 19.90 $h \pm 3.83$. Statistical analysis confirmed that $I_{50}$ from H5B14 is significantly lower than those from other mAbs (Additional file 6: Table S1). Thus, H5B14 binding to the RON PSI domain is superior over other anti-RON mAbs in induction of RON internalization.

\section{H5B14-based ADCs and their stability in human plasma} Schematic representatives of H5B14-MMAE and H5B14DCM are shown in Fig. 3a. Conjugation profiles of both H5B14-MMAE and H5B14-DCM (Fig. 3b) fitted those of ADCs formulated using the dipeptide linker as previously described $[4,5]$. Average DARs were 3.76:1 for H5B14MMAE and 3.72 for H5B14-DCM 3.72:1 (Fig. 3b). Stability analysis of H5B14-MMAE and H5B14-DCM in PBS at room temperature up to 28 days showed that both ADCs 


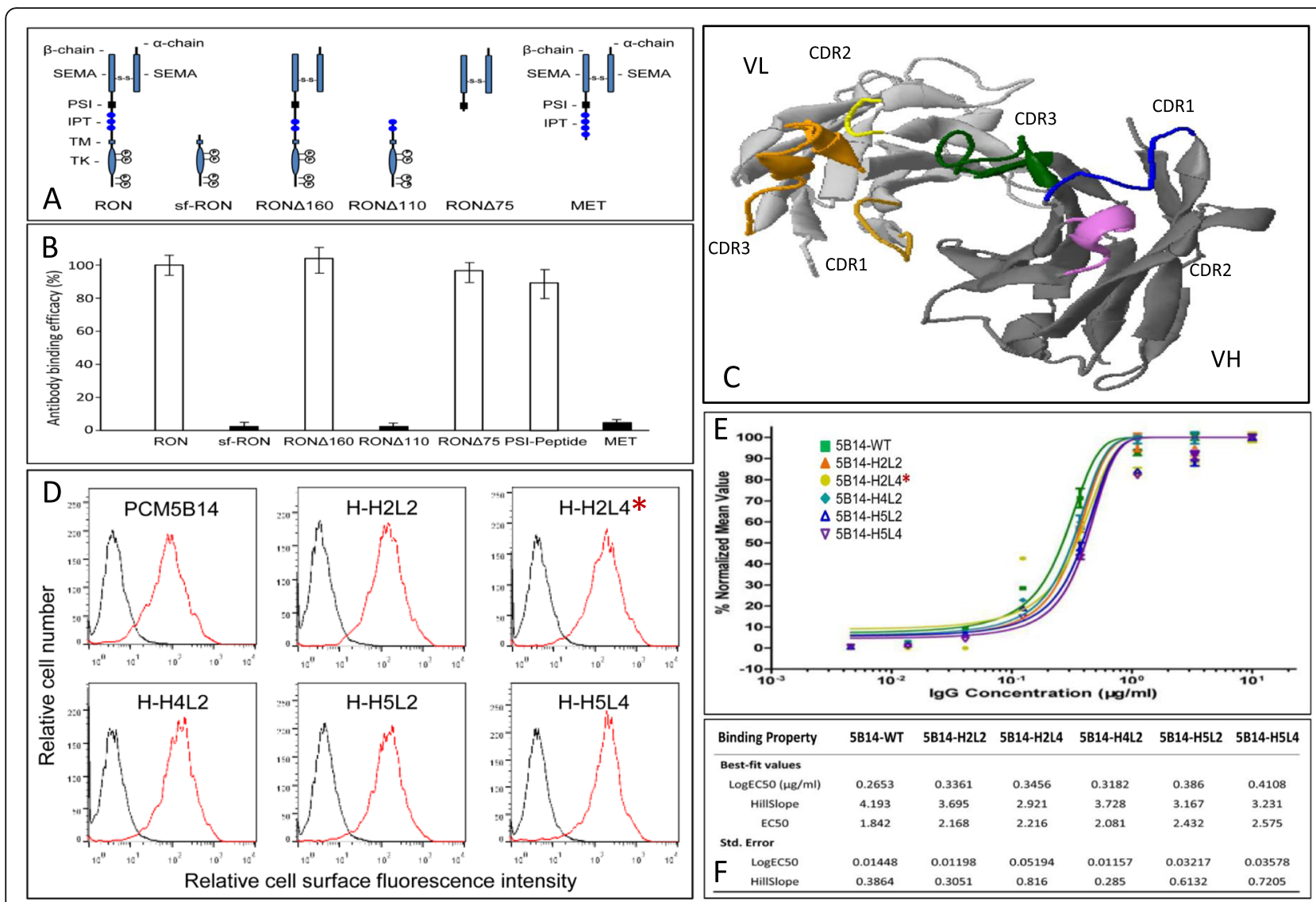

Fig. 1 Characterization of mouse mAb specific to the RON PSI domain and its humanization: a Schematic representation of RON, RON isoforms, and MET extracellular structure. Mature RON contains a $35 \mathrm{kDa}$ a-chain and a $145 \mathrm{kDa} \beta$-chain linked by a disulfide bond. SEMA, PSI and IPT domains are located in the $\beta$-chain. The listed four RON isoforms are shown with unique truncations and deletions either by alternative initiation or by mRNA splicing [8]. The MET extracellular structure is similar that of RON. b Direct ELISA for PCM5B14 reactive to the RON PSI domain. RON, RON isoforms, RON PSI peptides, and MET extracellular protein were coated at $150 \mathrm{ng}$ per well in triplicate in a 96-well plate. Goat-anti-mouse IgG coupled with HRP was used as the detecting antibody. Results are shown as the percentage of antibody-binding activity. PCM5B14 reactive to RON was set as 100\%. c Modeling of CDRs from PCM5B14 in human IgG heavy chain and light chain. The framework of human IgG1 molecule was used for PCM5B14 humanization. The models of PCM5B14 CDRs grafted in the variable regions of human lgG1 heavy chain and light chain were generated using the software Automatic Predictions of Immunoglobulin Structures (Tramontano at University of Rome, Italy). d Binding of humanized antibody subclones to RON expressed by HT-29 cells. Humanized lgG subclones at $1.5 \mu \mathrm{g}$ per ml were incubated with HT-29 cells followed by addition of goat anti-human lgG1 antibody coupled with FITC. Immunofluorescence intensity from individual samples was determined by flow cytometric analysis. $\mathbf{e}$ and $\mathbf{f}$ Analysis of binding affinities of humanized IgG subclones to human RON. Different amounts of humanized PCM5B14 subclones were incubated with NIH-3 T3 cells expressing human RON followed by addition of goat anti-human IgG1 antibody coupled with fluorescein isothiocyanate (FITC). Antibody-binding affinity was calculated as previously described [6]

are highly stable (Additional file 3: Figure S3). The obtained DAR at day 28 was 3.59 for H5B14-MMAE and 3.48 for H5B14-DCM. Both ADCs also were stable in human plasma with less than $6 \%$ of MMAE or DCM dissociated from the conjugates after incubation at $37^{\circ} \mathrm{C}$ for 10 days (Fig. 3c). These results indicate that H5B14-based ADCs are highly stable in PBS and in human plasma with minimal dissociation.

\section{Effect of H5B14-based ADCs on cancer cell viability}

Because H5B14 induces a robust RON internalization, we wanted to know the impact of H5B14-MMAE and H5B14-DCM on cancer cell viability. A time dependent study showed that both H5B14-MMAE and H5B14DCM decrease H358 cell viability at relatively early stages (Fig. 4a). As judged by the dose of $3.75 \mu \mathrm{g} / \mathrm{ml}$, H5B14-based ADCs progressively reduced cell viabilities from $100 \%$ to $\sim 60 \%$ and to $\sim 40 \%$ within $24 \mathrm{~h}$ to $48 \mathrm{~h}$, respectively. In contrast, cell viabilities treated with the same dose of $\mathrm{Zt} / \mathrm{g} 4$-based ADCs remained at 90\% and $\sim 55 \%$, respectively. These studies indicate that H5B14mediated drug delivery significantly reduces cell viability at the early stages after ADC treatment.

We then studied H5B14-mediated drug delivery in association with its efficacy. A panel of 15 cancer cell lines with variable RON expression was tested. Zt/g4-based 


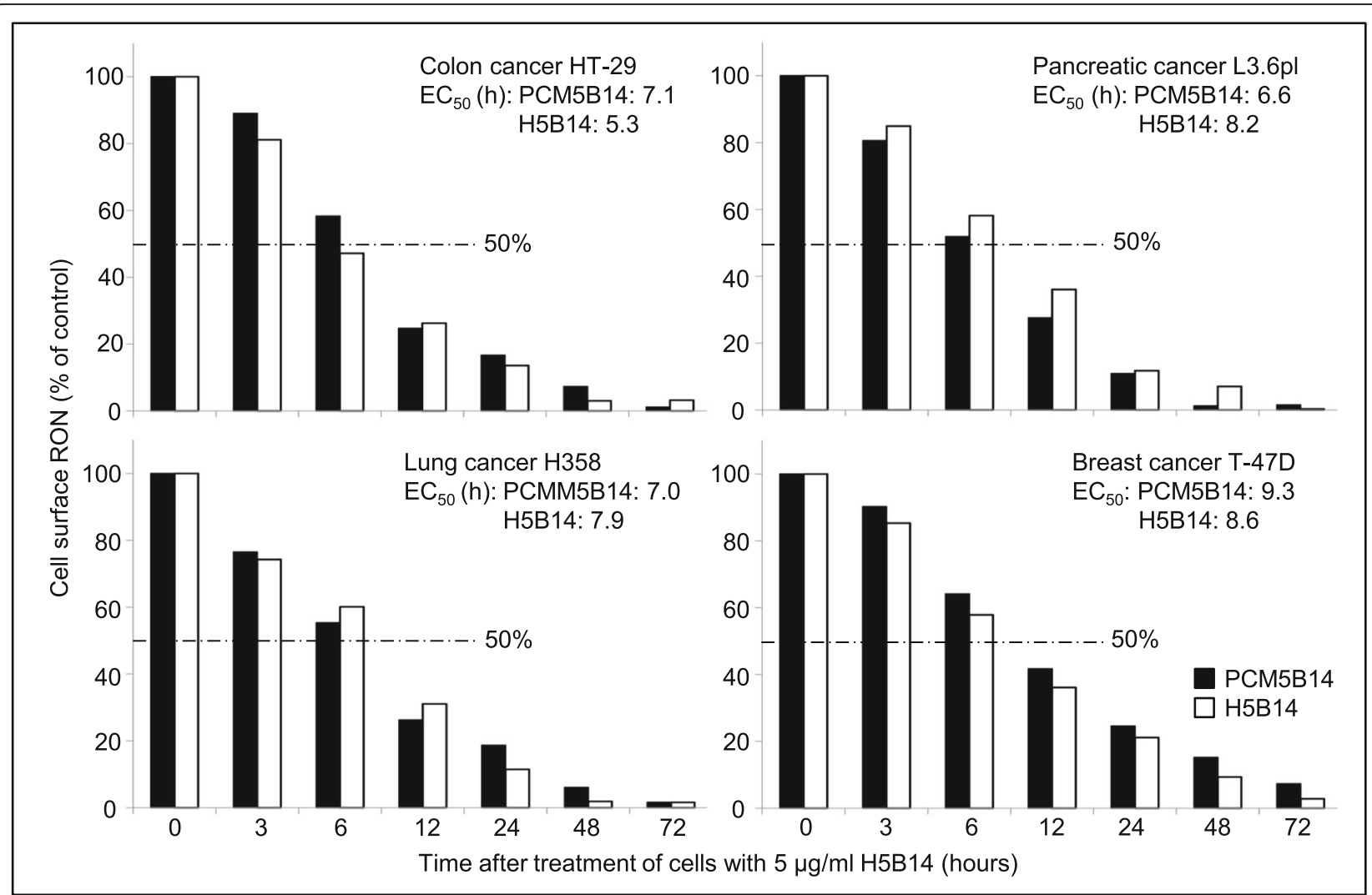

Fig. 2 H5B14-induced cell surface RON internalization: Four cancer cell lines HT-29, L3.6pl, H358, and T-47D at $1 \times 10^{6}$ cells per dish were treated at $37^{\circ} \mathrm{C}$ with $5 \mu \mathrm{g} / \mathrm{ml}$ of $\mathrm{H} 5 \mathrm{~B} 14$ or PCM5B14, collected at different time points, washed with acidic buffer to eliminate cell surface bound lgG [1], and then incubated with $2 \mu \mathrm{g} / \mathrm{mL}$ of anti-RON mAb Zt/c1 [23]. Immunofluorescence was analyzed by flow cytometer using FITC-coupled antimouse lgG. Immunofluorescence from cells treated with $\mathrm{H} 5 \mathrm{~B} 14$ at $4^{\circ} \mathrm{C}$ was set as $100 \%$. Internalization efficiency $\left(\mathrm{IC}_{50}\right)$ was calculated as the time required to achieve a $50 \%$ reduction of cell surface RON

ADCs served for comparison. H5B14-MMAE in a dosedependent manner significantly reduced cell viability in all RON-positive cell lines tested (Additional file 4: Figure S4A). Similar results were also obtained when H5B14-DCM was used (Additional file 4: Figure S4B). A summary of H5B14-based ADCs in reduction of cell viability with $\mathrm{IC}_{50}$ values is presented in Table 1 . It was noticed that the efficacy between H5B14- and Zt/g4-based ADCs is at comparable levels, although differences in induction of RON internalization existed between H5B14 and $\mathrm{Zt} / \mathrm{g} 4$ (Additional file 6: Table S1). The average $\mathrm{IC}_{50}$ at $72 \mathrm{~h}$ was $3.06 \pm 1.36 \mu \mathrm{g} / \mathrm{ml}$ for H5B14-MMAE, comparable to $2.95 \pm 1.52 \mu \mathrm{g} / \mathrm{ml}$ for Zt/g4-MMAE. Similarly, the average $\mathrm{IC}_{50}$ was $2.43 \pm 1.22 \mu \mathrm{g} / \mathrm{ml}$ for H5B14-DCM, similar to $2.61 \pm 1.36 \mu \mathrm{g} / \mathrm{ml}$ for $\mathrm{Zt} / \mathrm{g} 4-\mathrm{DCM}$. Thus, H5B14-based ADCs is as effective as Zt/g4-based ADCs in reduction of cell viability.

The relationship between the effect of H5B14-based $\mathrm{ADCs}$ on cell viability and the number of RON receptors expressed by cancer cells also was analyzed (Fig. 4b). A direct correlation was established by plotting the individual $\mathrm{IC}_{50}$ values against the cell surface number of $\mathrm{RON}$.
Although sensitivities of individual cell lines to ADCs were different, patterns of their responsiveness to H5B14-MMAE or H5B14-DCM were highly similar. We reasoned that the minimal number of cell-surface $\mathrm{RON}$ required for $\mathrm{H} 5 \mathrm{~B} 14$-based $\mathrm{ADCs}$ to achieve a 95\% reduction in cell viability is $\sim 8000$ molecules per cell. A decrease in the number of RON molecules correlate proportionally with the diminished efficacy of H5B14-based ADCs. Thus, cancer cells expressing $\sim 8000$ RON molecules per cell are in vitro required for H5B14-based ADCs to show maximal activities.

\section{Inhibitory effect of H5B14-based ADCs on spheroid formation and survival of cancer stem-like cells}

To determine H5B14-based ADCs in cancer stem-like cells, we first studied the effect of H5B14-MMAE and H5B14-DCM on spheroid formation using ASPC1, BxPc-3, and L3.6pl cell lines as the model. Treatment of individual cell lines with H5B14-based ADCs dramatically attenuated the ability of these cells to form spheroids (Fig. 5a). For example, the number of spheroids derived from BxPC-3 cells was significantly reduced. 

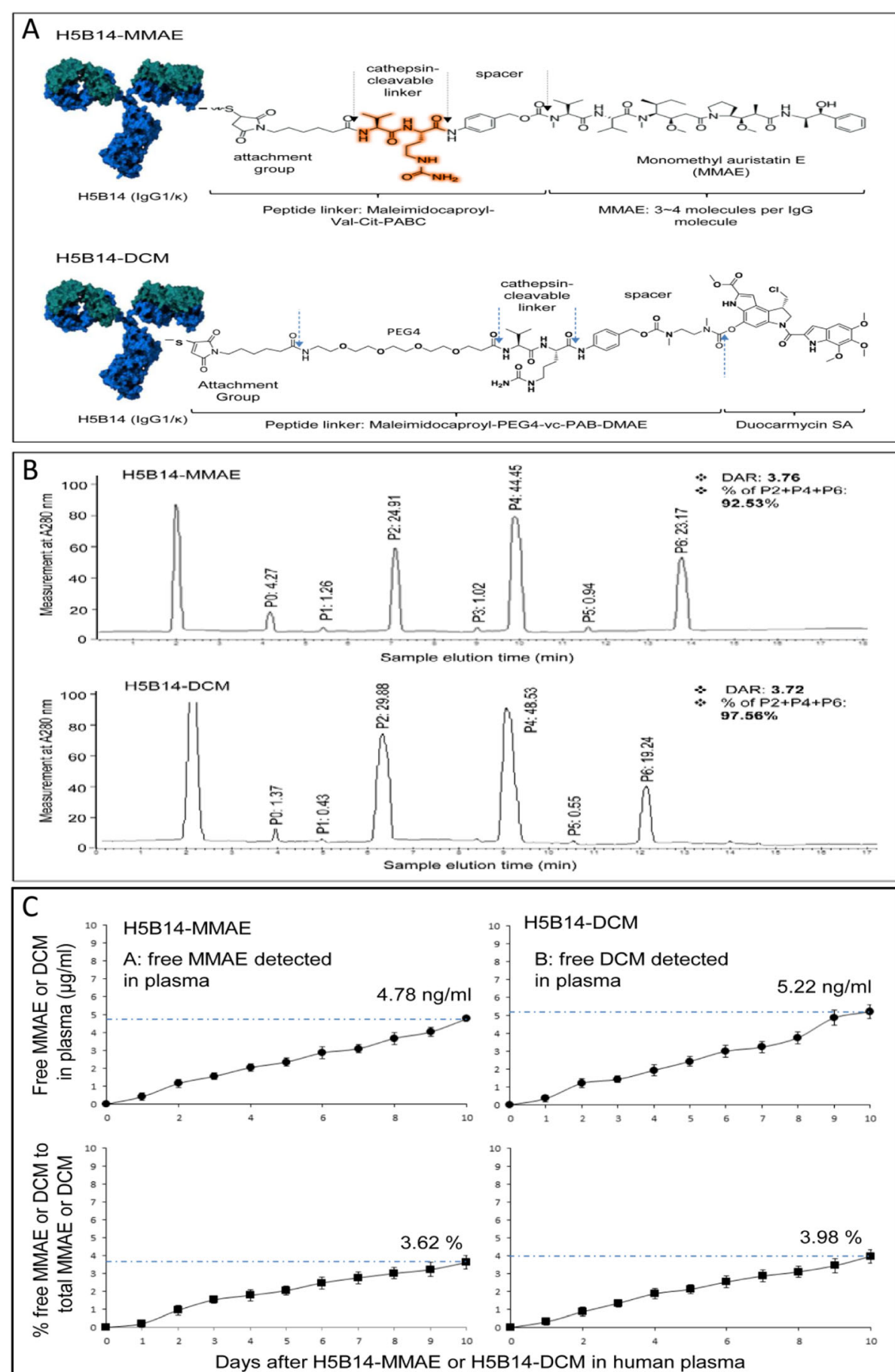

Fig. 3 Schematic Structures of H5B14-based ADCs, drug conjugation profiles, and their plasma stability: a Schematic representation of H5B14based ADCs. Both MMAE and duocarmycin [DCM] were conjugated to H5B14 by the valine-citruline dipeptide linker according to the manufacturer's instruction (www.concortis.com). b HIC analysis of MMAE and DCM conjugated to H5B14. Individual H5B15-MMAEs or H5B14DCMs with different numbers of MMAE or DCM [0-6] are marked as P0 to P6. The DAR combining P2, P4, and P6 was calculated at 3.76:1 for H5B14-MMAE and 3.73:1 for H5B14-DCM. c Dissociation MMAE or DCM from H5B14-based ADCs in human plasma. Both H5B14-MMAE and H5B14-DCM at $10 \mu \mathrm{g}$ per $\mathrm{ml}$ were incubated with fresh human plasma at $37^{\circ} \mathrm{C}$ for 10 days. The amount of free MMAE or DCM in plasma was determined using the LC-MS/MS method [35] with slight modifications [6]. Samples also were used for measuring MMAE or DCM conjugated H5B14 as detailed in Materials and Methods. A ratio from free MMAE to the total MMAE in H-Zt/g4-MMAE was calculated to determine the percentage of MMAE dissociated from $\mathrm{H}$-Zt/g4-MMAE 

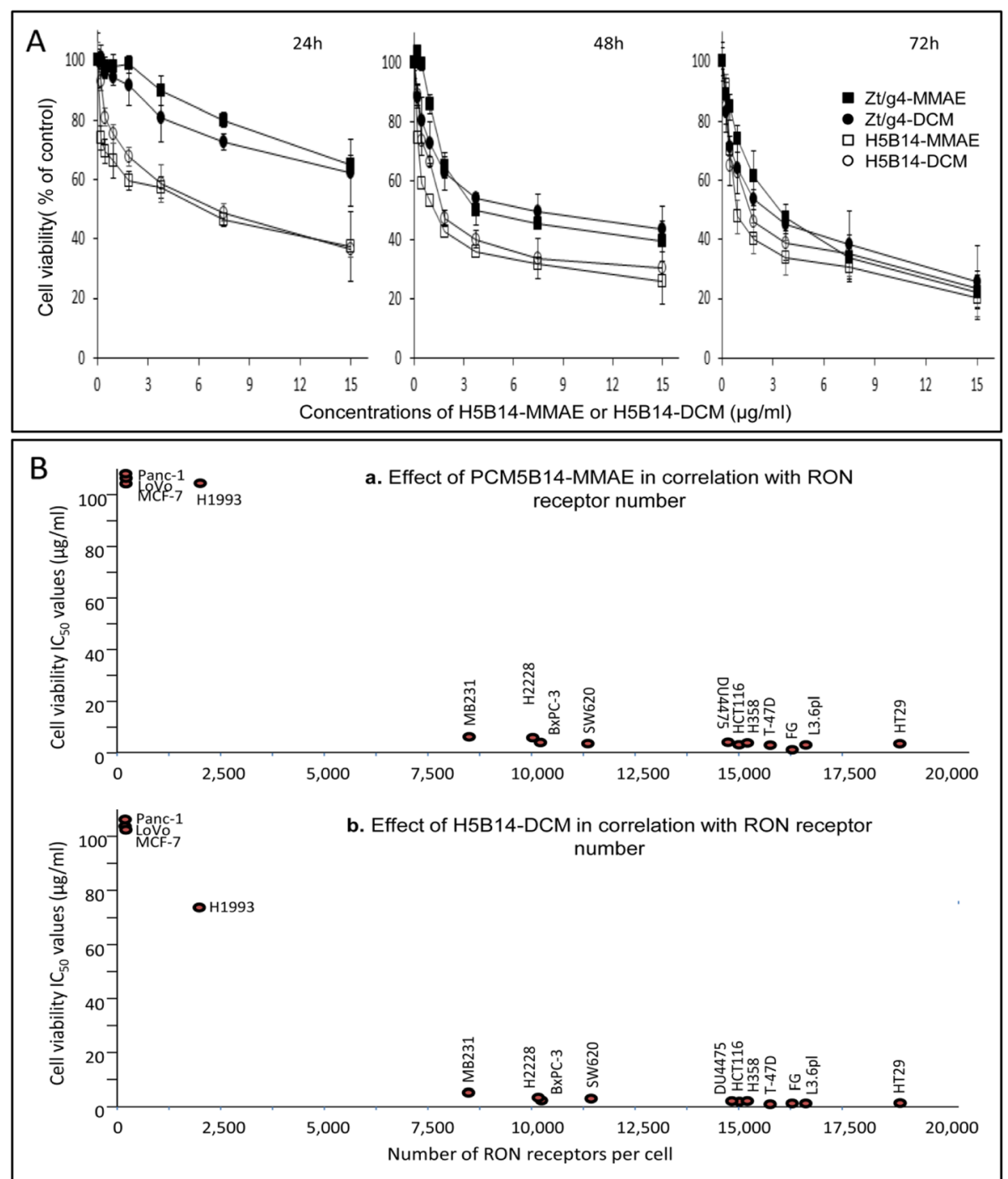

Fig. 4 Efficacy of H5B14-based ADCS in vitro on cell viability and its association with levels of RON expression: a Effect of H5B14-based ADCs on cancer cell viability. H358 cells (8000 cells per well in a 96-well plate in triplicate) were treated with different amounts of H5B14-MMAE or H5B14DCM for $72 \mathrm{~h}$. Cell viability was determined by the MTT assay. $\mathbf{b}$ Correlation between levels of RON expression and efficacy of H5B14-based ADCs. Cell viability $I_{50}$ values from a panel of 15 cancer cell lines expressing variable levels of RON were plotted with different numbers of RON expressed per cell. H5B14-based ADCs at the amount below $5 \mu \mathrm{g}$ per $\mathrm{ml}$ to achieve an $\mathrm{IC}_{50}$ value was used as the effective dose to determine the required receptor number to reach the $\mathrm{EC}_{95}$ value. The $\mathrm{IC}_{50}$ values for cell viability from individual groups were calculated using the GraphPad Prism 7 software. Results shown here are from one of two experiments with similar results

Similar results were also observed for spheroids formed by ASPC1 and L3.6pl cell lines (Fig. 5a). Thus, H5B14based ADCs have the ability to impair the spheroid formation mediated by PAC cells.

We then studied H5B14-based ADCs in induction of $\mathrm{PAC}^{\mathrm{SL}}$ cell death. PAC ${ }^{\mathrm{SL}}$ cells expressing RON, CD44, and ESA are known to be tumor-initiating stem-like cells $[36,37]$. H5B14-MMAE or H5B14-DCM treatment caused $\mathrm{PAC}^{\mathrm{SL}}$ cell death in a dose-dependent manner (Fig. 5b). Among three PAC ${ }^{\mathrm{SLC}}$ cell lines tested, the $\mathrm{IC}_{50}$ values were in the range of $\sim 2 \mu \mathrm{g}$ per ml for both H5B14- based ADCs, indicating that H5B14-based ADCs in vitro is capable of killing $\mathrm{PAC}^{\mathrm{SL}}$ cells.

Finally, we determined the effect of H5B14-based ADCs on FG cells expressing ALDH. Percentages of FG cells expressed ALDH were at relatively high levels $[\sim 60 \%$ of cells positive] (Fig. $5 \mathrm{c}$ and d). However, percentages of ALDH-positive cells were dramatically decreased to $8.4 \%$ in H5B14-MMAE treated cells and to $3.5 \%$ in H5B14DCM treated cells. These results suggest that H5B14based ADCs are effective in decreasing FG cells expressing ALDH. 
Table 1 Inhibitory effect of H5B14-based ADCs on cell viability from a panel of cancer cell lines

\begin{tabular}{|c|c|c|c|c|c|c|}
\hline \multirow{2}{*}{$\begin{array}{l}\text { Cancel cell } \\
\text { lines }\end{array}$} & \multicolumn{6}{|c|}{ IC50 values of H5B14-MMAE and H5B14-DCM in cell viability $(\mu \mathrm{g} / \mathrm{ml})^{\mathrm{a}}$} \\
\hline & Zt/g4-MMAE & $\mathrm{Zt} / \mathrm{g} 4-\mathrm{DCM}$ & PCM5B14-MMAE & PCM5B14-DCM & H5B14-MMAE & H5B14-DCM \\
\hline MCF-7 & $>100$ & $>100$ & $>100$ & $>100$ & $>100$ & $>100$ \\
\hline DU4475 & 2.28 & 3.96 & 2.75 & 2.46 & 3.04 & 1.81 \\
\hline MDA-MB-231 & 6.89 & 3.48 & 5.38 & 5.98 & 6.25 & 5.30 \\
\hline T-47D & 1.77 & 1.22 & 3.11 & 1.55 & 2.35 & 1.63 \\
\hline LoVo & $>100$ & $>100$ & $>100$ & $>100$ & $>100$ & $>100$ \\
\hline НCT-116 & 2.21 & 0.94 & 3.31 & 1.58 & 2.83 & 1.37 \\
\hline HT-29 & 1.65 & 1.65 & 3.15 & 2.97 & 2.88 & 2.09 \\
\hline SW-620 & 2.97 & 2.65 & 5.44 & 1.92 & 3.35 & 2.95 \\
\hline H1993 & $>100$ & 83.89 & $>100$ & $>100$ & $>100$ & 74.07 \\
\hline $\mathrm{H} 2228$ & 3.86 & 4.28 & 5.63 & 4.65 & 4.49 & 3.64 \\
\hline H358 & 3.85 & 2.96 & 2.77 & 3.51 & 1.46 & 1.87 \\
\hline Panc-1 & $>100$ & $>100$ & $>100$ & $>100$ & $>100$ & $>100$ \\
\hline BxPC-3 & 3.04 & 3.89 & 3.25 & 5.25 & 2.68 & 3.02 \\
\hline FG & 2.14 & 0.74 & 1.13 & 0.96 & 1.34 & 1.15 \\
\hline L3.6pl & 1.83 & 2.41 & 2.47 & 4.48 & 3.03 & 1.88 \\
\hline Average & $2.95 \pm 1.52$ & $2.61 \pm 1.36$ & $3.49 \pm 1.41$ & $3.21 \pm 1.68$ & $3.06 \pm 1.36$ & $2.43 \pm 1.22$ \\
\hline
\end{tabular}

andividual cancer cell lines at $\sim 8000$ cells per well were cultured in triplicate in the presence of absence of different amounts of H5B14-MMAE or H5B14-DCM for $72 \mathrm{~h}$. Zt/g4-based ADCs and PCM5B14-based ADCS were used for comparison. The MTS assay was used to determine the cell viability. The IC50 values for individual cell lines were calculated using the GraphPad Prism 7 software as previously described [1]

\section{Therapeutic efficacy of H5B14-based ADCs in multiple tumor xenograft models}

Both H5B14-MMAE and H5B14-DCM at $20 \mathrm{mg} / \mathrm{kg}$ in a single injection regimen were evaluated in mouse xenograft tumor models initiated by H358, HT-29, L3.6pl, and T-47D cell lines. LoVo cells served as the control. Injection of H5B14-MMAE inhibited the growth of xenograft tumors mediated by all four cell lines, respectively (Fig. 6a). The effect of H5B14-MMAE on H358 cell-mediated tumor growth appeared to be relatively weak (Fig. 6a). In contrast, H5B14-DCM inhibited tumor growth-mediated by all four cancer cell lines without visible differences (Fig. 6b). Considering the terminal half-life $\left[t^{1 / 2}: \sim 6.3\right.$ days] of humanized anti-RON ADCs in mice [1-6] and the tumor regrowth curve, we calculated tumoristatic concentrations [TSCs, the minimal concentrations required to balance tumor growth and inhibition]. TSCs for H5B14-MMAE treated animals were in the range of $0.63 \mathrm{mg}$ per $\mathrm{kg}$ for tumors mediated by HT-29, L3.6pl, and T-47D cells, respectively (Fig. 6a). TSCs for $\mathrm{H} 358$ xenograft tumors were in the range of $1.25 \mathrm{mg}$ per $\mathrm{kg}$. For H5B14-DCM treated mice, TSCs for all four tumor xenograft models were in the range of $0.63 \mathrm{mg} / \mathrm{kg}$ (Fig. 6b). The tumor regrowth appears to be at day 30 for both H5B14-based ADCs. The only exception was H358 xenograft tumors treated with H5B14MMAE, in which tumor regrowth was observed at day 24. Regardless these differences, results in Fig. $6 a$ and b demonstrate that H5B14-based ADCs at a single injection is highly effective and its activity is long lasting.

We further compared the tumor number and weight at the end of study. H5B14-MMAE reduced the average tumor weight by $85.24 \%$ for H358, $97.22 \%$ for HT-29, 98.37\% for $\mathrm{L} 3.6 \mathrm{pl}$, and $96.17 \%$ for $\mathrm{T}-47 \mathrm{D}$ xenograft tumors, respectively (Fig. 6c). Similarly, the average decrease in tumor weight caused by H5B14-DCM was 98.35\% for H358, 95.65\% for HT-29, 98.55\% for L3.6pl, and 99.53 for T-47D xenograft tumors, respectively (Fig. 6d). It is worthy to note that although tumors from H5B14-MMAE treated L3.6pl group were collected 8 days later [Day 24 for control mice versus day 32 for experimental group], a significant decrease in the average tumor weight was still observed (Fig. 6c). These results demonstrate that H5B14-based ADCs inhibits tumor growth leading to reduced tumor weight.

Both H5B14-MMAE and H5B14-DCM showed tumoreradicating activities (Fig. $6 \mathrm{c}$ and d). By counting the number of tumors eliminated from both ADC-treated mice, the effect of H5B14-DCM is slightly stronger than that of H5B14-MMAE. As noticed, H5B14-MMAE did not eradicate any tumors from the H358 xenograft model (Fig. 6c). In contrast, H5B14-DCM eliminated three tumors from the H358 tumor model (Fig. 6d). These results indicate that both H5B14-MMAE and H5B14-DCM at $20 \mathrm{mg} / \mathrm{kg}$ in a single injection are capable of eradicating tumor xenografts dependent on individual cell lines used. 

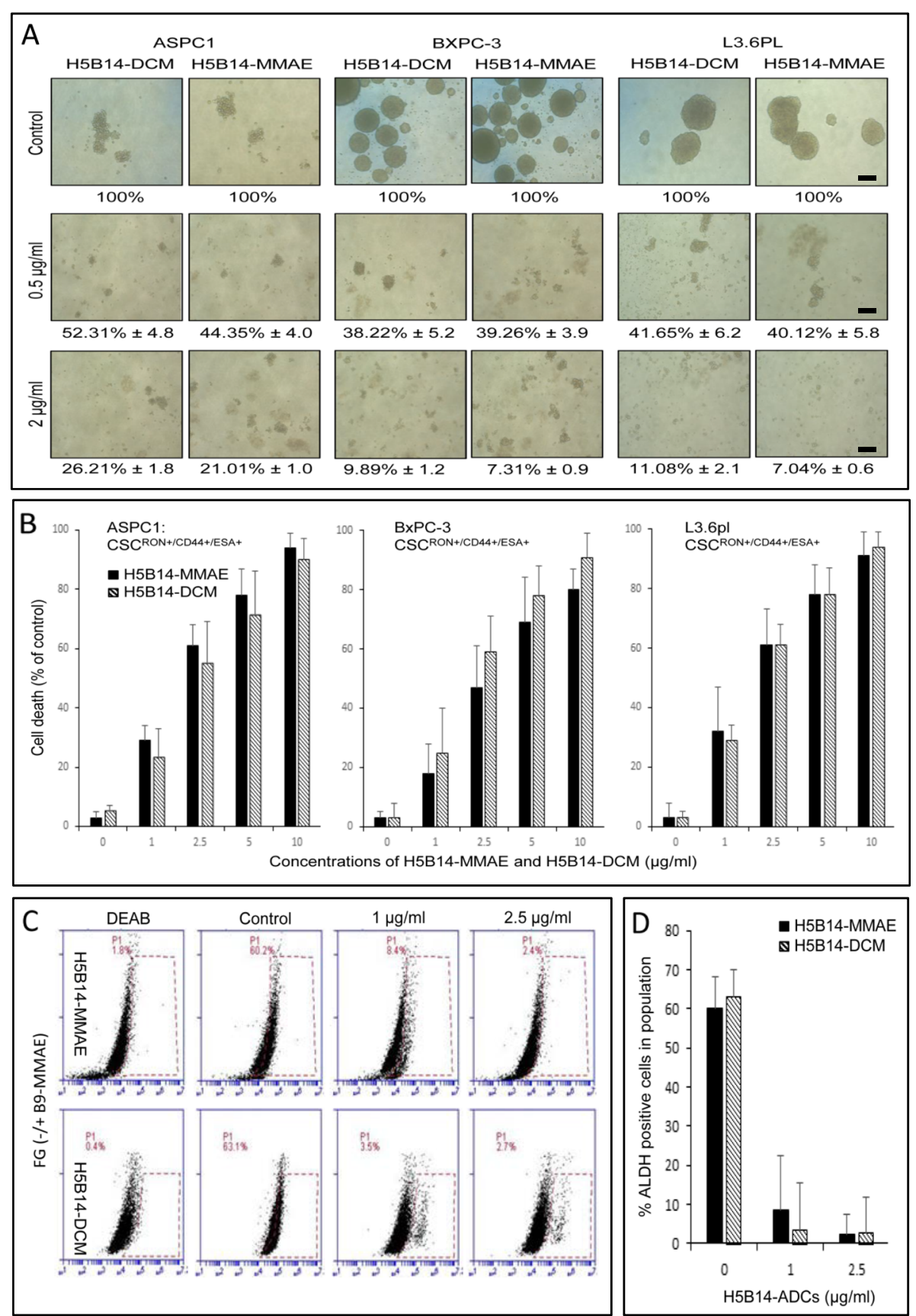

Fig. 5 Effect of H5B14-based ADCs on cancer stem cell-derived spheroid formation, cellular viability, and ALDH expression. a Inhibitory effect of H5B14-based ADCs on spheroid formation by pancreatic cancer cells. Spheroid formation from ASPC-1, BXPC3, and L3.6pl cells were performed as previously described [5,29]. H5B14-MMAE or H5B14-DCM was added after initiation of cell culture. The number of spheroids was counted 40 days after ADC treatment. Scale bar: $50 \mu \mathrm{M}$. b Death of pancreatic stem-like cells mediated by H5B14-based ADCs. PAC ${ }^{\mathrm{SL}} \mathrm{cells}_{\mathrm{s}}$ with $\mathrm{RON}^{+} / \mathrm{CD} 4^{+} / \mathrm{ESA}^{+}$ phenotypes were treated in triplicate with different amounts of H5B14-MMAE or H5B14-DCM for $72 \mathrm{~h}$. Cell death was determined by the trypan blue exclusion assay [1]. $\mathbf{c}$ and $\mathbf{d}$ Inhibitory effect of H5B14-based ADCs on pancreatic cancer cells expressing ALDH. FG cells expressing a relatively high level of ALDH were used as the model. After treatment of cells with H5B14-MMAE or H5B14-DCM for 48 h, the percentages of FG cells expressing ALDH were determined by using the ALDEFLUOR ${ }^{\mathrm{TM}}$ Kit according to the manufacture's instruction. Results shown here are from one of two experiments with similar results 

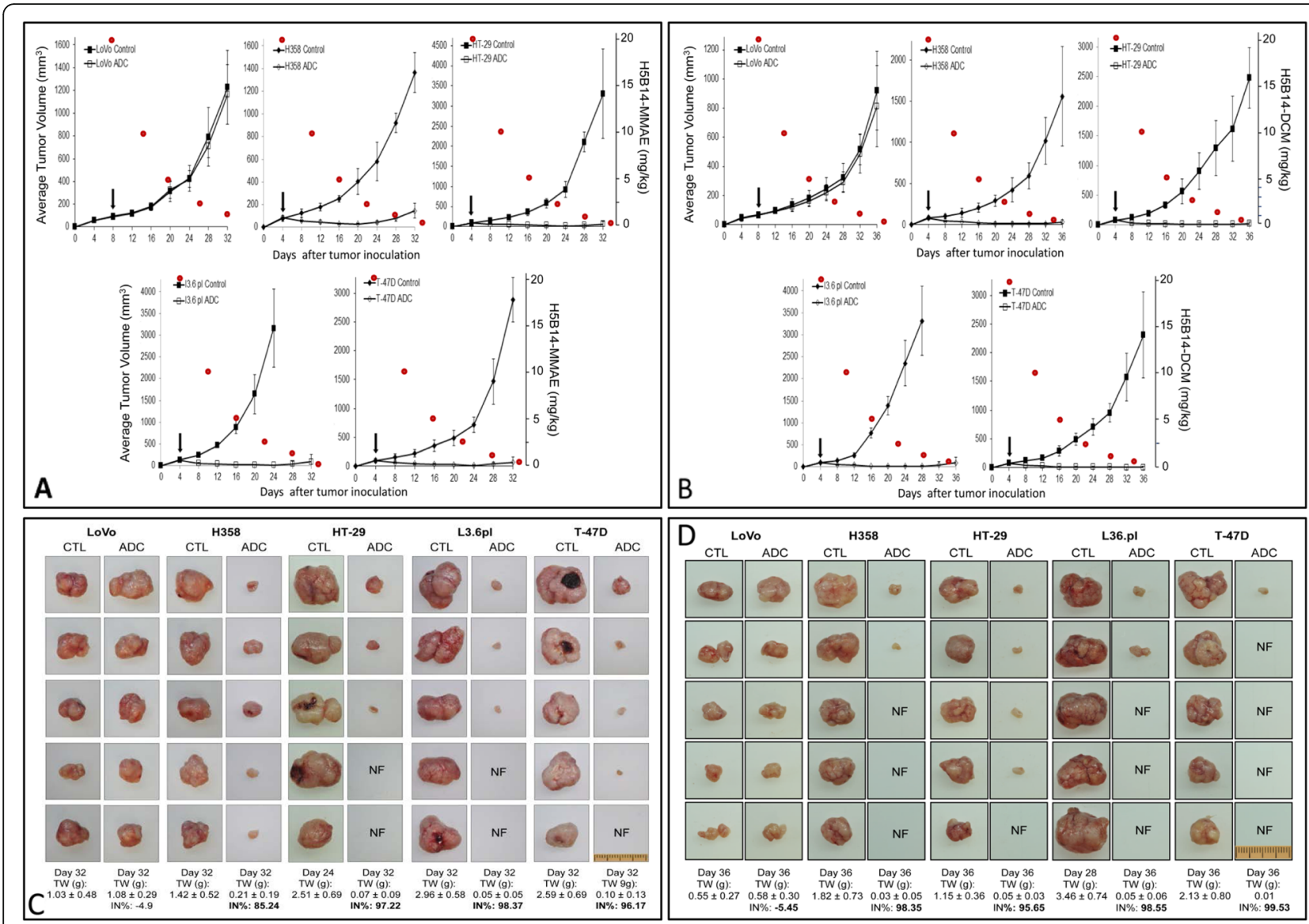

Fig. 6 Therapeutic efficacy of H5B14-based ADCs in multiple tumor xenograft models: a and b Inhibitory effect of H5B14-MMAE and H5B14-DCM on xenograft tumor growth. Tumors mediated by H358, HT-29, L3.6pl, and T-47D cell lines were used as the model. LoVo cell-derived tumors without RON expression served as the control. Athymic nude mice (5 mice per group) were subcutaneously inoculated with $5 \times 10^{6}$ cells. $\mathrm{H} 5 \mathrm{~B} 14$ MMAE (a) or H5B14-DCM (b) at $20 \mathrm{mg} / \mathrm{kg}$ in a single injection was administered through tail vein after tumors volumes reached $\sim 150 \mathrm{~mm}^{3}$. Mice injected with CmlgG-MMAE at $20 \mathrm{mg} / \mathrm{kg}$ were used as the control. To establish the effect-time relationship, the estimated reduction of H-Zt/g4MMAE in vivo according to the $t \frac{1}{2}$ was marked as red circles [6]. $\mathbf{c}$ and $\mathbf{d}$ Effect of H5B14-based ADCS on tumor weight and number. Individual tumors from different groups described in (a) and (b) were collected at the end of study. All tumors were weighed to reach the average tumor weight per group, which was used to obtain the percentages of tumor growth inhibition. The number of tumors was counted to determine the eradication effect of H5B14-based ADCs. NF, no tumors were found in the injected site

\section{Toxicological effect of H5B14-based ADCs in mouse bodyweight}

A single injection of H5B14-based ADCs at 40, 60, 80, and $100 \mathrm{mg} / \mathrm{kg}$ was used to determine the maximum tolerated dose in mice (Additional file 5: Figure S5). Mice receiving both H5B14-MMAE and H5B14-DCM up to $60 \mathrm{mg} / \mathrm{kg}$ within 12 days displayed the normal daily activity, food consumption, and bodyweight. However, both H5B14-MMAE and H5B14-DCM at $80 \mathrm{mg} / \mathrm{kg}$ caused a dramatic bodyweight reduction. Furthermore, death [three out of five mice] occurred in mice receiving $100 \mathrm{mg} / \mathrm{kg}$ H5B14-MMAE or H5B14-DCM. These studies imply that H5B14-based ADCs below $60 \mathrm{mg} / \mathrm{kg}$ is relatively safe in mice as judged by daily activity, food consumption, and bodyweight.

\section{Discussion}

The study presented here describes humanized antibody H5B14 specific to the RON PSI domain and its efficacy in the form of $\mathrm{ADC}$ for targeted cancer therapy. First, we generated H5B14 from mouse PCM5B14, which is highly specific to the RON PSI domain and confirmed that the binding of H5B14 to the PSI domain causes robust RON internalization, leading to effective drug delivery. Second, we demonstrated that H5B14-based ADCs are highly stable in human plasma with minimal dissociation within a prolonged period, which could have a favorable pharmacokinetic profile in vivo. Third, we confirmed that H5B14-based ADCs affect cancer cell viability in the early stages, inhibit spheroid formation, and cause cancer stem-like cell death. Fourth, we 
confirmed that a single injection of H5B14-based ADCs not only inhibits but also eradicates tumors in multiple xenograft models. Finally, we demonstrate that both H5B14-MMAE and H5B14-DCM are well tolerated up to $60 \mathrm{mg} / \mathrm{kg}$ in mice. Thus, H5B14-based ADCs are superior with tumor-eradicating activity, which warrants for clinical trials in the future.

ADC-mediated receptor internalization followed by intracellular drug processing is a critical step required for cancer cell killing [38-40]. Several strategies such as the use of mAbs recognizing distinct epitopes have been used to accelerate receptor internalization [40]. Also, a bispecific antibody targeting the lysosomal antigen has been applied to improve the payload delivery [41]. We have previously demonstrated that anti-RON mAb Zt/g4 specific to the RON SEMA domain causes RON internalization [1-6], which mimics the ligand-induced RON endocytosis [31, 32]. Nevertheless, the action of $\mathrm{Zt} / \mathrm{g} 4$ is moderated with an average internalization efficacy at 15 h [1-6]. To improve antibody-mediated intracellular drug delivery, we focused on mAbs targeting the PSI domain due to its unique location and function in the RON extracellular sequence $[7,8]$. The use of antibody specific to the PSI domain for induction of MET internalization has been reported [33]. However, the use of mAbs targeting the PSI domain for drug delivery has not been studied. By generating H5B14 from mouse PCM5B14, we demonstrated that H5B14 specific to the RON PSI domain rapidly induces robust RON internalization. Among three extracellular domains (SEMA, PSI and IPT) evaluated, H5B14 binding to the RON PSI domain appears to be most effective in induction of RON internalization with the average internalization efficacy at $\sim 9 \mathrm{~h}$. This is a significant improvement in comparison with other anti-RON mAbs recognizing the SEMA domain or the IPT motifs. Thus, the binding of antibodies to different regions in the RON extracellular sequences has an impact on RON internalization. Nevertheless, RON internalization is affected by other factors such as levels of RON expression. As shown in Fig. 4b, H5B14-mediated RON internalization is propositionally correlated with the number of RON molecules on the cell surface. Specifically, H5B14-mediated internalization appears to be more effective in cells expressing high number of RON in the cell surface.

The beneficial effect from increased RON internalization is evident in functional study. As shown in Fig. 4a, the inhibitory effect of H5B14-MMAE or H5B14-DCM on cell viability [more than $60 \%$ decrease] was observed as early as $24 \mathrm{~h}$ after cells were exposed to ADCs. Both H5B14MMAE and H5B14-DCM act equally. This effect is not observed in cells treated with $\mathrm{Zt} / \mathrm{g} 4$-based ADCs, which show the effect at relatively later stages due to its moderate internalization activity. For example, the significant reduction of cell viability caused by Zt/g4-based ADCs [more than $60 \%$ reduction] was only documented $72 \mathrm{~h}$ after drug treatment. Thus, H5B14-mediated rapid RON internalization leads to effective drug delivery and therefore has the pharmacological advances in controlling cancer cell growth and survival. Such activity could have a potential clinical implication.

Functional studies also demonstrate the inhibitory and/or cytotoxic effects of H5B14-Based ADCs on cancer stem-like cells. As a biomarker, RON expression is sustained in cancer stem-like cells including those from pancreatic and breast cancer cells [5, 6, 29]. Targeting RON using mAbs or tyrosine kinase inhibitors has been shown to eradicate cancer stem-like cells $[5,6,29]$. We showed here that H5B14-based ADCs are effective in inhibition of spheroid formation derived from PAC stemlike cells. Also, these ADCs are capable of causing death of $\mathrm{PAC}^{\mathrm{SL}}$ cells with $\mathrm{RON}^{+} / \mathrm{CD} 44^{+} / \mathrm{ESA}^{+}$phenotypes. $\mathrm{PAC}^{\mathrm{SL}}$ cells are known as tumor-initiating cells capable of self-renewal and pluripotency [36, 37]. We further confirmed that H5B14-based ADCs are capable of decreasing the percentages of FG cells expressing ALDH, a reliable cancer stem cell marker for solid tumors [42]. These findings highlight the importance of potential use of H5B14-based ADCs for targeting cancer stem-like cells to inhibit and/or to eradicate tumor-initiating cells in vivo.

The efficacy of H5B14-based ADCs in vivo was confirmed in multiple tumor xenograft models. The reasons to select H358, HT-29, L3.6pl, and T-47D cell lines for generating xenograft tumors were based on their tissue originality, malignant status, RON expression level, and responsiveness in vitro to anti-RON ADCs. Moreover, the rate of tumor growth in vivo is different among them. For example, L3.6pl cell-mediated tumors grew extremely fast. In contrast, tumor growth mediated by H358 cells was relatively slow. Consideration of these facts helped us to objectively evaluate the efficacy of H5B14-based ADCs in vivo. The rationale of using H5B14-based ADCs at $20 \mathrm{mg} / \mathrm{kg}$ in a single injection as the treatment regimen was to determine the relationship between the effective doses of ADCs and the duration of their activity. Humanized ADCs conjugated either with MMAE or DM1 has a $t^{1 / 2}$ of $\sim 6.3$ days in mouse [1-6]. Thus, the use of a relatively high dose in a single injection regimen should help establish a dose-dependent efficacy in correlation with the $t^{1 / 2}$ of ADCs.

Results presented in Fig. 6 confirm that both H5B14MMAE and H5B14-DCM are effective in inhibition and/or eradication of multiple tumor xenografts. Administration of H5B14-MMAE or H5B14-DCM immediately prevented xenograft tumor growth and caused a continued reduction in tumor volume in all models tested. Both ADCs are capable of inhibiting tumor growth regardless their origination 
or rate of tumor growth. Although differences existed between two ADCs in inhibition of tumor growth, both ADCs show a long-lasting effect as evident by the lack of tumor regrowth at day 32 for H5B14-MMAE treated mice and at day 36 for H5B14-DCM treated mice. These activities were confirmed after five-cycles of the $t^{1 / 2}$ of ADCs. One exception is H358 xenograft tumors treated with H5B14-MMAE, in which tumor regrowth was observed at day 28 . By analyzing curves of tumor growth, it appears that the efficacy of H5B14-MMAE is slight weak in comparison with that of H5B14-DCM. This notion was supported by measuring the average tumor weight and by accounting the number of tumors eradicated from both ADC-treated animals. As shown in Fig. $6 \mathrm{c}$ and d, tumor eradication was observed in all xenograft models treated with H5B14-DCM with a total of 11 tumors eliminated. However, H5B14-MMAE-mediated tumor eradication was observed only in three tumor xenograft models with a total of five tumors eliminated. No eradication was observed in H358 cell-mediated tumors. Considering these facts, we believe that the use of a relatively high dose of H5B14-based ADCs in the initial phase to inhibit and eradicate tumor xenografts could be an interesting strategy for RON-targeted cancer therapy.

\section{Conclusions}

ADCs targeting the RON receptor with significantly improved therapeutic index are the key for the success in cancer therapy. Currently, antibody-based biotherapeutics specific to RON are under intensive evaluation in both preclinical models and clinical trials. The results shown here indicate that humanized anti-RON mAb H5B14 targeting the RON PSI domain, leading to increased cytotoxic drug delivery and effective inhibition and/or eradication of multiple xenograft tumors, is an attractive strategy for generation of RON-targeted ADCs for potential clinical application. Our study highlights the importance of selecting anti-RON mAbs with unique features for ADC development and lays the foundation for using H5B14-based ADCS for clinical trials in the future.

\section{Supplementary information}

Supplementary information accompanies this paper at (https://doi.org/10. 1186/s40425-019-0732-8).

Additional file 1: Figure S1. Schematic representation of procedures for generation of mouse mAbs specific to the RON PSI domain. (A) Structure and sequence of the human RON PSI domain. A peptide containing 43 amino acids from Gly526 to Pro568 corresponding to the entire PSI domain was presented. (B) The synthetic peptide conjugated to KLH was used for mouse immunization. Individual hybridomas cell lines were obtained through classical methods for mouse mAb production. The mAbs specific to the RON PSI domain such as PCM5B14 were verified by ELISA, immunoprecipitation, and immunofluorescence analyses.
Additional file 2: Figure S2. Interaction of $\mathrm{H} 5 \mathrm{~B} 14$ with $\mathrm{RONs}$ from different species. Stable NIH3T3 cells expressing human, monkey, or mouse RON were incubated in duplicate with different amounts of H5B14 followed by goat anti-human lgG coupled with FITC. Immunofluorescent intensities from individual samples were determined by flow cytometric analysis. Results are shown as the percentages of H5B14 specific binding to RON. The binding affinity (IC50) was calculated using the GraphPad Prism 7 software.

Additional file 3: Figure S3. Stability of H5B14-based ADCs in PBS. H5B14-MMAE and H5B14-DCM at $10 \mu \mathrm{g} / \mathrm{ml}$ were incubated with $1 \mathrm{ml}$ PBS at room temperature for 28 days. Samples were collected at different time intervals and analyzed by HIC. Individual peaks with different numbers of MMAE or DCM conjugated to H5B14 were marked as P0 to P6. The average DAR combining P2, P4, and P6 for both ADCs were calculated accordingly [1-3].

Additional file 4: Figure S4. The concentration-dependent effect of H5B14-based ADCs on cell viability. A panel of fifteen cancer cell lines expressing variable levels of RON was used as the model. Cells at 8000 cells per well in a 96-well plate in triplicate were treated with different amounts of H5B14-MMAE (A) or H5B14-DCM (B) for $72 \mathrm{~h}$. Cell viability was determined by the MTT assay. Zt/g4-MMAE or Zt/g4-DCM were used for comparison.

Additional file 5: Figure S5. Effect of H5B14-based ADCs on mouse bodyweight. Female athymic nude mice (five mice per group) were injected with H5B14-MMAe or H5B14-DCM at 40,60, 80, and $100 \mathrm{mg} / \mathrm{kg}$ in a single dose through the tail vein, respectively. Animals were monitored daily for activity, responsiveness, food consumption, and others. Individual mice were weighted every day to reach an average bodyweight for each group. All animals were sacrificed at the end of the study.

Additional file 6: Table S1. Efficacy of H5B14-Mediated RON Internalization in Comparison with Other Anti-RON mAbs.

\section{Abbreviations}

ADC: Antibody-drug conjugates; CDR: Complementarity-determining region; CRC: Colorectal cancer; DAPI: 4',6-diamidino-2-phenylindole; DAR: Drug to antibody ratio; DM1: Maytansinoid derivative 1; ELISA: Enzyme-linked immunosorbent assay; ESA: Epithelial-specific antigen; FITC: Fluorescein isothiocyanate; HIC: Hydrophobic interaction chromatography; KLH: Keyhole limpet hemocyanin; LC-MS/MS: Liquid chromatography with tandem mass spectrometry; mAb: Monoclonal antibodies; MET: Mesenchymal-epithelial transition; MMAE: Monomethyl auristatin E; MTT: 3-(4, 5- dimethylthiazolyl-2)2, 5 diphenyltetrazolium bromide; PDC: Pancreatic adenocarcinoma; PK: Pharmacokinetic; RON: Recepteur d'origine nantais

\section{Acknowledgements}

We thank Drs. AM Lowy for FG cells and GE Gallick for L3.6pl cells. We greatly appreciate Ms. Susan Denney and Ms. Rachel Hudson (TTUHSC School of Pharmacy in Amarillo, TX) for editing the manuscript.

\section{Authors' contributions}

X-MT, T-HW, C-YH, Y-ZL, Z-GW, and H-PY carried out antibody production, purification, characterization, and humanization. LF and SRS performed ADC conjugation, HIC analysis, and in vitro cellular and in vivo mouse experiments. X-MT, H-PY, and M-HW designed the entire experiments, supervised the study, analyzed experimental data, prepared figures \& tables, and wrote/ revised manuscript. All authors approved the manuscript for submission and publication.

\section{Funding}

This work was supported in part by funds from Major Project of Zhejiang Provincial Science and Technology Department \#2019C03038 (XMT); and by National Natural Sciences Foundation of China grant \#81872883 (HPY). 


\section{Ethics approval and consent to participate}

The use of athymic nude mice for in vivo studies was approved by TTUHSC Institutional Animal Use Committee.

\section{Consent for publication}

Not applicable.

\section{Competing interests}

The authors declare that they have no competing interests.

\section{Author details}

'Department of Hematology, Zhejiang Provincial People's Hospital, Hangzhou Medical College, Hangzhou, China. ${ }^{2}$ Cancer Biology Research Center, Texas Tech University Health Sciences Center School of Pharmacy, Amarillo, TX, USA. ${ }^{3}$ Department of Pharmaceutical Sciences, Texas Tech University Health Sciences Center School of Pharmacy, Amarillo, TX, USA. ${ }^{4}$ State Key Laboratory for Diagnosis \& Treatment of Infectious Diseases, First Affiliated Hospital, Zhejiang University School of Medicine, Hangzhou, China. ${ }^{5}$ National Clinical Research Center for Infectious Diseases, First Affiliated Hospital, Zhejiang University School of Medicine, Hangzhou, China.

\section{Received: 22 April 2019 Accepted: 4 September 2019}

\section{Published online: 13 September 2019}

\section{References}

1. Feng L, Yao HP, Wang W, Zhou YQ, Zhou J, Zhang R, Wang MH. Efficacy of anti-RON antibody Zt/g4-drug maytansinoid conjugation (anti-RON ADC) as a novel therapeutics for targeted colorectal cancer therapy. Clin Cancer Res. 2014:20:6045-58

2. Yao HP, Feng L, Zhou JW, Zhang RW, Wang MH. Therapeutic evaluation of monoclonal antibody-maytansinoid conjugates as a model of RONtargeted drug delivery for pancreatic cancer treatment. Am J Cancer Res. 2016;6:937-56.

3. Feng L, Yao HP, Zhou YQ, Zhou J, Zhang R, Wang MH. Biological evaluation of antibody-maytansinoid conjugates as a strategy of RON targeted drug delivery for treatment of non-small cell lung cancer. J Exp Clin Cancer Res. 2016;35:70.

4. Yao HP, Feng L, Weng TH, Hu CY, Suthe SR, Mostofa AGM, Chen LH, Wu ZG, Wang WL, Wang MH. Preclinical efficacy of anti-RON antibody-drug conjugate Zt/g4-MMAE for targeted therapy of pancreatic cancer overexpressing RON receptor tyrosine kinase. Mol Pharm. 2018;15:3260-71.

5. Suthe SR, Yao HP, Weng TH, Hu CY, Feng L, Wu ZG, Wang MH. RON receptor tyrosine kinase as a therapeutic target for eradication of triplenegative breast cancer: efficacy of anti-RON ADC Zt/g4-MMAE. Mol Cancer Ther. 2018;17:2654-64.

6. Yao HP, Feng L, Suthe SR, Chen LH, Weng TH, Hu CY, Jun ES, Wu ZG, Wang WL, Kim SC, Tong XM, Wang MH. Therapeutic efficacy, pharmacokinetic profiles, and toxicological activities of humanized antibody-drug conjugate Zt/g4-MMAE targeting RON receptor tyrosine kinase for cancer therapy. J ImmunoTherapy Cancer. 2019;7:75.

7. Ronsin C, Muscatelli F, Mattei MG, Breathnach R. A novel putative receptor protein tyrosine kinase of the met family. Oncogene. 1993;8:1195-202.

8. Yao HP, Zhou YQ, Zhang R, Wang MH. MSP-RON signaling in cancer: pathogenesis and therapeutic potential. Nat Rev Cancer. 2013;13:466-81.

9. Thomas RM, Toney K, Fenoglio-Preiser C, Revelo-Penafiel MP, Hingorani SR, Tuveson DA, Waltz SE, Lowy AM. The RON receptor tyrosine kinase mediates oncogenic phenotypes in pancreatic cancer cells and is increasingly expressed during pancreatic cancer progression. Cancer Res. 2007:67:6075-82.

10. Maggiora P, Marchio S, Stella MC, Giai M, Belfiore A, De Bortoli M, Di Renzo MF, Costantino A, Sismondi P, Comoglio PM. Overexpression of the RON gene in human breast carcinoma. Oncogene. 1998;16:2927-33.

11. Wang MH, Lee W, Luo YL, Weis MT, Yao HP. Altered expression of the RON receptor tyrosine kinase in various epithelial cancers and its contribution to tumorigenic phenotypes in thyroid cancer cells. J Pathol. 2007;213:402-11.

12. Kanteti R, Krishnaswamy S, Catenacci D, Tan YH, EL-Hashani E, Cervantes G, Husain AN, Tretiakova M, Vokes EE, Huet H, Salgia R. Differential expression of RON in small and non-small cell lung cancers. Genes Chromosom Cancer. 2012;51:841-51.
13. Lee WY, Chen HH, Chow NH, Su WC, Lin PW, Guo HR. Prognostic significance of co-expression of RON and MET receptors in node-negative breast cancer patients. Clin Cancer Res. 2005;11:2222-8.

14. Yu PT, Babicky M, Jaquish D, French R, Marayuma K, Mose E, Niessen S, Hoover H, Shields D, Cheresh D, Cravatt BF, Lowy AM. The RONreceptor regulates pancreatic cancer cell migration through phosphorylation-dependent breakdown of the hemidesmosome. Int J Cancer. 2012;131:1744-54.

15. Ma Q, Guin S, Padhye SS, Zhou YQ, Zhang RW, Wang MH. Ribosomal protein $\mathrm{S} 6$ kinase (RSK)-2 as a central effector molecule in RON receptor tyrosine kinase mediated epithelial to mesenchymal transition induced by macrophage-stimulating protein. Mol Cancer. 2011;10:66.

16. Zhao S, Ammanamanchi S, Brattain M, Cao L, Thangasamy A, Wang J, Freeman JW. Smad4-dependent TGF-beta signaling suppresses RON receptor tyrosine kinase-dependent motility and invasion of pancreatic cancer cells. J Biol Chem. 2008;283:11293-301.

17. Logan-Collins J, Thomas RM, Yu P, Jaquish D, Mose E, French R, Stuart W, McClaine R, Aronow B, Hoffman RM, Waltz SE, Lowy AM. Silencing of RON receptor signaling promotes apoptosis and gemcitabine sensitivity in pancreatic cancers. Cancer Res. 2010;70:1130-40.

18. Wang D, Shen Q, Chen YQ, Wang MH. Collaborative activities of macrophage-stimulating protein and transforming growth factor-beta1 in induction of epithelial to mesenchymal transition: roles of the RON receptor tyrosine kinase. Oncogene. 2004;23:1668-80.

19. Zhou YQ, He C, Chen YQ, Wang D, Wang MH. Altered expression of the RON receptor tyrosine kinase in primary human colorectal adenocarcinomas: generation of different splicing RON variants and their oncogenic potential. Oncogene. 2003;22:186-97.

20. Chakedis J, French R, Babicky M, Jaquish D, Howard H, Mose E, Lam R, Holman P, Miyamoto J, Walterscheid Z, Lowy AM. A novel protein isoform of the RON tyrosine kinase receptor transforms human pancreatic duct epithelial cells. Oncogene. 2016;35:3249-59.

21. Bardella C, Costa B, Maggiora P, Patane S, Olivero M, Ranzani GN, De Bortoli M, Comoglio PM, Di Renzo MF. Truncated RON tyrosine kinase drives tumor cell progression and abrogates cell-cell adhesion through E-cadherin transcriptional repression. Cancer Res. 2004:64:5154-61.

22. Yao HP, Zhuang CM, Zhou YQ, Zeng JY, Zhang RW, Wang MH. Oncogenic variant RON160 expression in breast cancer and its potential as a therapeutic target by small molecule tyrosine kinase inhibitor. Curr Cancer Drug Targets. 2013;13:686-97.

23. Yao HP, Luo YL, Feng L, Cheng LF, Lu Y, Li W, Wang MH. Agonistic monoclonal antibodies potentiate tumorigenic and invasive activities of splicing variant of the RON receptor tyrosine kinase. Cancer Biol Ther. 2006;5:1179-86

24. Li Z, Yao H, Guin S, Padhye SS, Zhou YQ, Wang MH. Monoclonal antibody [mAb]-induced down-regulation of RON receptor tyrosine kinase diminishes tumorigenic activities of colon cancer cells. Int J Oncol. 2010;37:473-82.

25. Yao HP, Zhou YQ, Ma Q, Guin S, Padhye SS, Zhang RW, Wang MH. The monoclonal antibody Zt/f2 targeting RON receptor tyrosine kinase as potential therapeutics against tumor growth-mediated by colon cancer cells. Mol Cancer. 2011:10:82.

26. Lambert JM, Berkenblit A. Antibody-drug conjugates for cancer treatment. Annu Rev Med. 2018:69:191-207.

27. Sievers EL, Senter PD. Antibody-drug conjugates in cancer therapy. Annu Rev Med. 2013:64:15-29.

28. Guin $\mathrm{S}$, Yao HP, Wang MH. RON receptor tyrosine kinase as a target for delivery of chemo- drugs by antibody directed pathway for cancer cell cytotoxicity. Mol Pharm. 2010;7:386-97.

29. Padhye SS, Guin S, Yao HP, Zhou YQ, Zhang R, Wang MH. Sustained expression of the RON receptor tyrosine kinase by pancreatic cancer stem cells as a potential targeting moiety for antibody-directed chemotherapeutics. Mol Pharm. 2011:8:2310-9.

30. Wagh PK, Peace BE, Waltz SE. Met-related receptor tyrosine kinase Ron in tumor growth and metastasis. Adv Cancer Res. 2008;100:1-33.

31. Chao KL, Tsai IW, Chen C, Herzberg O. Crystal structure of the Sema-PSI extracellular domain of human RON receptor tyrosine kinase. PLoS One. 2012;7:e41912.

32. Chao KL, Gorlatova NV, Eisenstein E, Herzberg O. Structural basis for the binding specificity of human recepteur d'origine nantais (RON) receptor tyrosine kinase to macrophage-stimulating protein. J Biol Chem. 2014 289:29948-60. 
33. Park H, Kim D, Kim E, Sa JK, Lee HW, Yu S, Oh J, Kim SH, Yoon Y, Nam DH. Tumor inhibitory effect of IRCR201, a novel cross-reactive c-Met antibody targeting the PSI domain. Int J Mol Sci. 2017;18:E1968.

34. Liu XY, Pop LM, Vitetta ES. Engineering therapeutic monoclonal antibodies. Immunol Rev. 2008;222:9-27.

35. Sanderson RJ, Nicholas ND, Baker Lee C, Hengel SM, Lyon RP, Benjamin DR, Alley SC. Antibody-conjugated drug assay for protease-cleavable antibodydrug conjugates. Bioanalysis. 2016;8:55-63.

36. Li C, Heidt DG, Dalerba P, Burant CF, Zhang L, Adsay V, Wicha M, Clarke MF, Someone DM. Identification of pancreatic cancer stem cells. Cancer Res. 2007:67:1030-7.

37. Jung J, Lee CH, Seol HS, Choi YS, Kim E, Lee EJ, Rhee JK, Singh SR, Jun ES, Han B, Hong SM, Kim SC, Chang S. Generation and molecular characterization of pancreatic cancer patient-derived xenografts reveals their heterologous nature. Oncotarget. 2016;7:62533-46.

38. Durbin KR, Phipps C, Liao X. Mechanistic modeling of antibody-drug conjugate internalization at the cellular level reveals inefficient processing steps. Mol Cancer Ther. 2018;17:1341-51.

39. Maass KF, Kulkarni C, Betts AM, Wittrup KD. Determination of cellular processing rates for a trastuzumab-maytansinoid antibody-drug conjugate (ADC) highlights key parameters for ADC design. AAPS J. 2016;18:635-46.

40. Pedersen MW, Jacobsen HJ, Koefoed K, Hey A, Pyke C, Haurum JS, Kragh M. Sym004: a novel synergistic anti-epidermal growth factor receptor antibody mixture with superior anticancer efficacy. Cancer Res. 2010;70:588-97.

41. de Goeij BE, Vink T, Ten Napel H, Breij EC, Satijn D, Wubbolts R, Miao D, Parren PW. Efficient payload delivery by a bispecific antibody-drug conjugate targeting HER2 and CD63. Mol Cancer Ther. 2016;15:2688-97.

42. Rodriguez-Torres M, Allan AL. Aldehyde dehydrogenase as a marker and functional mediator of metastasis in solid tumors. Clin Exp Metastasis. 2016;33:97-113.

\section{Publisher's Note}

Springer Nature remains neutral with regard to jurisdictional claims in published maps and institutional affiliations.

Ready to submit your research? Choose BMC and benefit from:

- fast, convenient online submission

- thorough peer review by experienced researchers in your field

- rapid publication on acceptance

- support for research data, including large and complex data types

- gold Open Access which fosters wider collaboration and increased citations

- maximum visibility for your research: over $100 \mathrm{M}$ website views per year

At $\mathrm{BMC}$, research is always in progress.

Learn more biomedcentral.com/submissions 